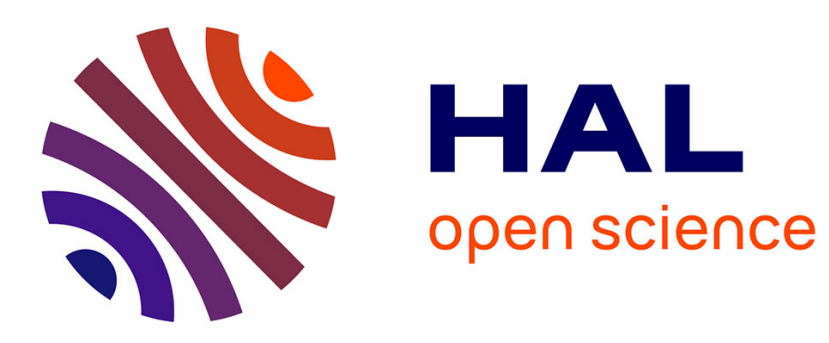

\title{
About the lekton: Response to Max Kölbel
}

François Recanati

\section{To cite this version:}

François Recanati. About the lekton: Response to Max Kölbel. Ilse Depraetere; Raf Salkie. Semantics and Pragmatics: Drawing a Line, 11, Springer, 2017, Logic, Argumentation and Reasoning, 10.1007/978-3-319-32247-6_13. ijn_01446367

\section{HAL Id: ijn_01446367 \\ https://hal.science/ijn_01446367}

Submitted on 25 Jan 2017

HAL is a multi-disciplinary open access archive for the deposit and dissemination of scientific research documents, whether they are published or not. The documents may come from teaching and research institutions in France or abroad, or from public or private research centers.
L'archive ouverte pluridisciplinaire HAL, est destinée au dépôt et à la diffusion de documents scientifiques de niveau recherche, publiés ou non, émanant des établissements d'enseignement et de recherche français ou étrangers, des laboratoires publics ou privés. 


\section{Metadata of the chapter that will be visualized online}

\begin{tabular}{|c|c|c|}
\hline Chapter Title & \multicolumn{2}{|c|}{ About the lekton: Response to Max Kölbel } \\
\hline Copyright Year & \multicolumn{2}{|l|}{2017} \\
\hline Copyright Holder & \multicolumn{2}{|c|}{ Springer International Publishing Switzerland } \\
\hline \multirow[t]{7}{*}{ Corresponding Author } & Family Name & Recanati \\
\hline & Particle & \\
\hline & Given Name & François \\
\hline & Suffix & \\
\hline & Organization & École Normale Supérieure \\
\hline & Address & Paris, France \\
\hline & Email & recanati@ens.fr \\
\hline Abstract & \multicolumn{2}{|c|}{$\begin{array}{l}\text { In earlier work on so-called moderate relativism, I distinguished three } \\
\text { semantic levels: (i) the meaning of the sentence, (ii) the lekton (a typically } \\
\text { 'relativized' proposition, true at some situations and false at others), and } \\
\text { (iii) the Austinian proposition (the lekton together with a topic situation } \\
\text { serving as circumstance of evaluation). The lekton can be construed as a } \\
\text { property of situations or a type of situation. The Austinian proposition is } \\
\text { true iff the topic situation is of the type corresponding to the lekton. } \\
\text { In his contribution to this volume, Max Kölbel expresses a few worries } \\
\text { about my framework. First, he finds the psychological considerations } \\
\text { I offer in support of the intermediate notion (the lekton) insufficient: } \\
\text { a properly semantic justification is needed, he argues (and he provides } \\
\text { one). Second, he worries about my thesis that the lekton is 'fully } \\
\text { articulated', because it conflicts with the contextualist claim (defended } \\
\text { by myself in many writings) that 'what is said' is porous and hospitable } \\
\text { to unarticulated constituents. Third, he discusses potentially unwelcome } \\
\text { implications of my view in connection with faultless disagreement. } \\
\text { In this response I consider the three issues raised by Kölbel, along } \\
\text { with his suggestions for tackling them. I endorse Kölbel's semantic } \\
\text { argument for the lekton while dismissing his objection to the claim of } \\
\text { full articulatedness. Regarding faultless disagreement, I attempt to make } \\
\text { sense of it from a classical expressivist standpoint. }\end{array}$} \\
\hline
\end{tabular}

Keywords Unarticulated constituents - lekton - Austinian proposition - 


\begin{abstract}
In earlier work on so-called moderate relativism, I distinguished three 4 semantic levels: (i) the meaning of the sentence, (ii) the lekton (a typically 5 'relativized' proposition, true at some situations and false at others), and (iii) 6 the Austinian proposition (the lekton together with a topic situation serving as 7 circumstance of evaluation). The lekton can be construed as a property of situations 8 or a type of situation. The Austinian proposition is true iff the topic situation is of 9 the type corresponding to the lekton.

In his contribution to this volume, Max Kölbel expresses a few worries about 11 my framework. First, he finds the psychological considerations I offer in support 12 of the intermediate notion (the lekton) insufficient: a properly semantic justification 13 is needed, he argues (and he provides one). Second, he worries about my thesis 14 that the lekton is 'fully articulated', because it conflicts with the contextualist claim 15 (defended by myself in many writings) that 'what is said' is porous and hospitable to 16 unarticulated constituents. Third, he discusses potentially unwelcome implications 17 of my view in connection with faultless disagreement. 18

In this response I consider the three issues raised by Kölbel, along with his 19 suggestions for tackling them. I endorse Kölbel's semantic argument for the lekton 20 while dismissing his objection to the claim of full articulatedness. Regarding 21 faultless disagreement, I attempt to make sense of it from a classical expressivist 22 standpoint.

Keywords Unarticulated constituents - lekton • Austinian proposition • Rela- 24 tivized propositions $\bullet$ Faultless disagreement

In Perspectival Thought, I distinguish three semantic levels: (i) the meaning of the 26 sentence, (ii) the lekton (a typically 'relativized' proposition, true at some situations 27 and false at others), and (iii) the Austinian proposition (the lekton together with a 28 topic situation serving as circumstance of evaluation). The lekton can be construed 29

\footnotetext{
F. Recanati $(\bowtie)$

École Normale Supérieure, Paris, France

e-mail: recanati@ens.fr

(C) Springer International Publishing Switzerland 2017

I. Depraetere, R. Salkie (eds.), Semantics and Pragmatics: Drawing a Line,

Logic, Argumentation \& Reasoning 11, DOI 10.1007/978-3-319-32247-6_13
} 


\section{Author's Proof}

as a property of situations or a type of situation. The Austinian proposition is true 30 iff the topic situation is of the type corresponding to the lekton.

This analysis is more complex than the standard analysis which only distin- 32 guishes the meaning of the sentence and the (classical, unrelativized) proposition 33 that it expresses. My analysis posits an intermediate level, the lekton. The lekton is 34 referentially loaded, in contrast to sentence meaning, but it falls short of determining 35 absolute truth-conditions. The lekton falls short of determining absolute truth- 36 conditions because some determinants of truth-conditions are left unarticulated and 37 are provided by the situation. The lekton itself is 'fully articulated': nothing is in 38 the lekton that does not correspond to some element in the sentence. What is not 39 articulated can still affect truth-conditions, but only via the topic situation (which 40 serves as circumstance of evaluation for the lekton). So, in 'it is raining', the place 41 and time are unarticulated (that's the difference with 'it's raining here' and 'it's 42 raining now'), but they still affect truth-conditions via the topic situation: if the 43 topic situation is the situation here and now, the utterance is true iff it is raining in 44 that situation (here and now). So the truth-conditions of 'it is raining', 'it is raining 45 here' and 'it is raining now' are the same, but the lekta differ: an element that is 46 unarticulated in 'it is raining' is articulated and incorporated into the lekton in 'it is 47 raining here' and 'it is raining now'. The difference has psychological significance, 48 I argue, and it is missed by theories which only appeal to two levels (sentence 49 meaning and absolute truth-conditions).

Although sympathetic, Max Kölbel expresses a few worries. First, he finds the 51 psychological considerations I offer in support of the intermediate notion (the 52 lekton) insufficient: a properly semantic justification is needed, he argues (and he 53 provides one). Second, he worries about the idea that the lekton is 'fully articulated', 54 because it conflicts with the contextualist claim (defended by myself in Literal 55 Meaning) that 'what is said' is porous and hospitable to unarticulated constituents. 56 Third, he discusses potentially unwelcome implications of my view in connection 57 with faultless disagreement.

I am grateful to Kölbel for raising these issues and offering friendly amendments 59 or extensions of my view for dealing with them. I will consider the three issues in 60 turn, along with Kölbel's suggestions.

Kölbel is not convinced by the psychological reasons I offer for distinguishing the 63 lekta in 'it is raining' and 'it is raining now'. I say that the thought 'it is raining now' 64 requires on the part of the subject an explicit representation of the time of thought, 65 while the thinker of 'it is raining' may be 'temporally innocent' (i.e. not even able 66 to entertain such representations). Kölbel objects that the subject who thinks 'it is 67 raining' and the subject who thinks 'it is raining now' can both be credited with 68 time awareness. I agree, but I think one should distinguish between different sorts 69 of time awareness, and also distinguish between actuality and requirement. 


\section{Author's Proof}

13 About the lekton: Response to Max Kölbel

What the thought 'it is raining now' requires of its subject is an explicit 71 representation of the time of thought, contrasted with other times. Such an explicit 72 and contrastive representation is objective in the sense that the present time is 73 viewed as one particular time among others. The subject who thinks 'It is raining 74 now' is implicitly contrasting the present time, a rainy one, with some other time(s): 75 the property of being a time at which rain occurs is ascribed to the former in contrast 76 to the latter. The idea that the thinker of 'It is raining' might be temporally innocent 77 is a colourful way of saying that 'It is raining' does not require such an explicit, 78 objective representation of time; that thought is available also to those subjects 79 who lack the advanced conceptual ability to think about times qua elements of 80 an objective chronology (e.g. animals), but who are nevertheless able to register 81 the weather in their environment. Such subjects can still think 'It is raining'. Their 82 thought 'concerns' the time at which they occur but are not 'about' that time, in 83 contrast to 'it is raining now', which is about the time of thought. 84

In his work on the self notion, Perry has insisted on the difference between 85 primitive self-knowledge based on special, egocentric ways of gaining information 86 and acting, and objective self-knowledge based on the ability to think of oneself also 87 from a third-person point of view, as one person among others. ${ }^{1}$ I agree with Perry: 88 The distinction between the two kinds of representation is essential to the theory 89 of indexical thought. The self is unarticulated in primitive self-knowledge, while 90 objective self-knowledge rests on deploying a self concept (or a self file) which 91 explicitly represents the subject of thought (Perry 1986). I agree with Perry that such 92 a mental file requires 'the capacity to pool the information I get in normally other- 93 directed ways that happens to be about myself, with the primitive self-knowledge 94 I have concerning myself' (Perry 2014: 29). Because of that extra requirement, 95 objective self-knowledge is more demanding than primitive self-knowledge, which 96 it presupposes. Certain de se thoughts, which I call 'implicit', express primitive self- 97 knowledge and are available to any subject endowed with primitive self-knowledge; 98 other de se thoughts, which I call 'explicit', require possessing a self file based on 99 the capacity Perry talks about: the capacity to pool first person and third person 100 information about oneself. These two levels are similar to those we find in the 101 temporal case. The time is explicitly represented only in 'it's raining now' (and 102 the place only in 'It is raining here'). In 'it's raining' it is left unarticulated, as Prior 103 suggested. ${ }^{2}$ Temporal or locational concepts are deployed in one case, not in the 104 other.

With respect to implicit de se thoughts, Lewis's theory applies: the thinking sub- 106 ject serves as 'circumstance of evaluation' for the de se content, construed as a prop- 107 erty which the subject self-ascribes (Lewis 1979). But explicit de se thoughts are a 108 different matter: when a self file is deployed, the thought is explicitly about the sub- 109

\footnotetext{
${ }^{1}$ For a recent statement of Perry's view, see his Romanell lecture (Perry 2014).

2 "Tensed propositions are understood as directly or indirectly characterising the unmentioned time of utterance" (Prior 1977: 30).
} 
ject, who is incorporated into the lekton. The self occurs 'as object' in the thought, 110 while in implicit de se thought it merely occurs 'as subject' (Wittgenstein 1958). 111

Be that as it may, Kölbel offers a semantic justification for holding that 'it is 112 raining' and 'it is raining here' (or 'it is raining now') carry distinct lekta. The 113 indexicals 'now' and 'here' are rigid and their reference cannot be shifted by 114 circumstantial operators. In the case of 'it's raining', the place of evaluation can 115 be shifted: 'it is raining' is typically evaluated at the place of utterance, but in 116 'somewhere, it is raining' the place of utterance drops out of the picture: it does not 117 survive the shift induced by the operator 'somewhere'. Following Dummett, Evans, 118 Lewis and others, we can use that criterion to distinguish the lekton (Dummett's 119 'ingredient sense'; Lewis's 'semantic value') and the full assertoric content (the 120 Austinian proposition, in my framework). ${ }^{3}$ The assertoric content of 'it's raining' 121 and 'it's raining here' are the same, these authors argue, but their embedding profiles 122 are different. If we prefix 'it is raining' with 'somewhere', the place of utterance no 123 longer affects the truth-conditions. It does not survive operator-shifting, so it must be 124 left out of the lekton. Not so with 'it is raining here': the place of utterance is fixed by 125 the indexical as an element of content that survives operator shifting ('somewhere 126 it is raining here'). As Kölbel points out, the unshiftability of indexicals provides 127 ample justification for including the reference of indexicals in the lekton. In 'It's 128 raining', the place affects the truth-conditions via the topic situation (the situation 129 here and now). In 'it is raining here' it is a constituent of the lekton.

I fully endorse Kölbel's semantic criterion. My three-level framework is inherited 131 from Kaplan, whose 'contents' are relativized to time and world. Kaplanian contents 132 contrast both with sentence meaning (which is referentially unloaded) and full 133 assertoric content (what we get when we specify the circumstance with respect 134 to which the content is to be evaluated). Now the main justification adduced 135 by Kaplan for his intermediate notion of content is the rigidity/unshiftability of 136 indexicals, whose referential content survives operator-shifting. I agree with Kölbel 137 that that property is fundamental, and I think it is instantiated also in the realm of 138 thought.

Indexical concepts are unshiftable, in the sense that if you deploy such a 140 concept in thinking a counterfactual thought or holding a counterfactual attitude, 141 the reference of the indexical concept survives the shift away from the actual world 142 induced by the counterfactual attitude. In the counterfactual attitudes, the reference 143 of indexical concepts is fixed by actual world relations, yet the referents may be 144 rationally ascribed properties incompatible with their standing in such relations 145 (Ninan 2008). That means that the individuals found in the actual environment are 146 transported in imagination into possible worlds where these very individuals may 147 or may not instantiate the environmental properties which make it possible for us to 148 think about them in the first place.

\footnotetext{
${ }^{3}$ See Dummett (1973: 446-47; 1981: 572-74; 1993: 47-50), Evans (1979) and Lewis (1980).
} 


\section{Author's Proof}

13 About the lekton: Response to Max Kölbel

\subsection{2.}

I say that the lekton is fully articulated, and Kölbel concludes that what I called 'what is said' in previous writings should not be equated to the lekton, despite the fact that 'lekton' means 'what is said' in Greek. The reason why the lekton cannot be equated to what is said is that, according to my earlier account, what is said is 'nonminimal' - it is affected by modulation processes such as free enrichment-while, 155 according to Perspectival Thought, the lekton cannot contain any 'unarticulated 156 constituent'. Whatever unarticulated constituents there are are constituents of the 157 complete content, or Austinian proposition: they are aspects of the circumstance 158 of evaluation. So it seems that my earlier 'what is said' should be equated to 159 the Austinian proposition rather than to the lekton. Or, Kölbel suggests, perhaps 160 it should be equated to the utterance's truth-conditions, which correspond to an 161 equivalence class of Austinian propositions.

Kölbel objects to all this, on the grounds that, for various reasons, the lekton 163 should play the roles which I ascribe to 'what is said' (input to the inferential process 164 of implicature generation, content of the attitudes and of speech acts etc.); so it is 165 unfortunate that they wind up not being the same thing. If we fix the theory so that 166 they come out identical, as Kölbel suggests we should, then, given my insistence 167 that the lekton is fully articulated, we arrive at a position strikingly different from 168 that which I defend in Literal Meaning. According to the position we arrive at, 169 Kölbel says, the Austinian proposition is non-minimal (it contains unarticulated 170 constituents) but the lekton just is the minimal proposition which I deride in Literal 171 Meaning as having no psychological reality and no interesting role to play in the 172 theory. To sum up, there is, to say the least, a significant tension between Literal 173 Meaning and Perspectival Thought.

I deny that there is any such tension. I agree with Kölbel that the lekton should 175 be equated to what is said for all the reasons he gives. Indeed their being identical 176 is one of the reasons why I use that term 'lekton' which means 'what is said' (and 177 additionally conveys the suggestion of semantic incompleteness, due to the use of 178 the term by Stoic logicians in connection with tensed propositions). But how can 179 they be identical if one of them is minimal and the other one not?

Well, I never said that the lekton was minimal, and I don't think it is. The lekton 181 is the rich 'what is said' of Literal Meaning. How, then, can I maintain that the 182 lekton is fully articulated, that whatever is in the lekton must correspond to some 183 constituent in the sentence that expresses that lekton? Is not free enrichment, the 184 paradigmatic modulation process, the provision of unarticulated constituents? $\quad 185$

No it is not. In free enrichment some aspect of meaning is contributed in a top 186 down manner by the context. This is often interpreted as the provision of 'unar- 187 ticulated constituents', but that is not my interpretation. Free enrichment typically 188 corresponds to a process of specifization, through which we make the contextual 189 meaning of a lexical item more specific than its literal (conventional) meaning. Is 190 this a matter of providing unarticulated constituents? No. The contextualmeaning, 191 
resulting from free enrichment, is not unarticulated, because it corresponds to 192 something in the sentence, namely the lexical item whose meaning has been made 193 contextually more specific.

Consider a sentence like 'he opened the door'. This is understood in context 195 as a particular kind of opening-the standard kind rather than an opening of 196 the door with a scalpel (as when we open a wound). In context the opening 197 may be taken to involve a particular instrument (as in 'he took out his key and 198 opened the door'). The kind of opening at stake, the instrument etc.-all these 199 contextual aspects of the interpretation result from modulating (more specifically, 200 'enriching') the lexical meaning of 'open' by providing further specifications. That 201 process of free enrichment is optional and context-driven, in contrast to saturation, 202 which is linguistically mandated; yet the contextually specific content contributed 203 by the word is articulated, by definition, since it is the contextually specific 204 content contributed by the word. My claim that the lekton is fully articulated is 205 therefore compatible with its being non-minimal, i.e. affected by free processes of 206 modulation. ${ }^{4}$

I discuss faultless disagreement in Perspectival Thought, but the conclusions I reach 209 are very tentative. I start from the idea that agreement and disagreement are over 210 the complete content (involving the lekton and the situation of evaluation). If two 211 people entertain the same lekton but evaluate it with respect to distinct situations, 212 they don't disagree even if they ascribe opposite truth-values to the utterance: 213

I call you on the phone, and commenting upon my situation I say 'It is raining'. If you 214 say 'No, it isn't', meaning that there is no rain in your situation, there is misunderstanding 215 rather than genuine disagreement. Or, adapting Barwise's example, suppose that Holmes 216 says 'The salt is left of the pepper', and Watson, speaking from his own perspective, replies 217 'No it is not'. Clearly, there is no substantive disagreement here. If each of them is talking 218 about his own perspective, there is misunderstanding rather than genuine disagreement. 219 The same considerations apply to the temporal case. At time $t$, you say 'It is raining'. Later, 220 when the sun is shining again, you say 'It is not raining'. You cannot conclude 'so I was 221 wrong'. Here, as Richard points out, genuine disagreement can only be about temporally 222 specific contents. (Recanati 2007: 90-91)

Faultless disagreement seems to be a counterexample: people who disagree about 224 e.g. matters of taste seem to evaluate the same lekton (e.g. the relativized proposition 225 that vegemite is tasty) with respect to their respective standards of taste, and end 226 up with distinct truth-values when the standards are sufficiently different. Thus 227 vegemite is tasty to you, but not to me. You say 'Vegemite is tasty'; I respond: 'No, 228

\footnotetext{
${ }^{4}$ The claim of full articulatedness amounts to a ban on so-called 'topmost modulation' (see Recanati 2010: 22-23). For a recent argument that there is topmost modulation (hence that the lekton is not fully articulated), see Cohen and Kehler forthcoming.
} 


\section{Author's Proof}

13 About the lekton: Response to Max Kölbel

it is disgusting'. The disagreement here seems genuine, but there is no complete 229 content which the discussants share and over which they disagree. They only share 230 the lekton (that vegemite is tasty) but evaluate it with respect to their respective 231 standards. The complete contents of their respective thoughts are therefore different: 232 subject A evaluates the lekton with respect to A's standards of taste (and ends 233 up with the value 'true'), while B evaluates the same lekton with respect to B's 234 different standards (and ends up with the value 'false'). So what is going on? What 235 explains the difference between the 'it's raining' case, in which there is no genuine 236 disagreement, and the vegemite case, in which it seems that there is? 237

In my framework 'vegemite is tasty' expresses a relativized proposition, whose 238 truth or falsity is relative to a judge (a standard of taste). The judge (the person 239 for whom vegemite is tasty) is incorporated into the lekton in 'vegemite is tasty 240 to me', but in 'vegemite is tasty' it is left unarticulated and is contributed at the 241 Austinian proposition level. There is another difference between 'vegemite is tasty 242 and 'vegemite is tasty to me', however. 'Vegemite is tasty' has an objective flavour 243 (in many contexts at least) ${ }^{5}$ while 'vegemite is tasty to me' or 'I find it tasty' are 244 more subjective. According to Perspectival Thought, what accounts for the objective 245 flavour of 'vegemite is tasty' is the fact that the relevant judge is the community 246 to which both the speaker and the hearer belong. What exactly counts as 'the 247 community' is a highly context-sensitive matter, however, and this gives us a good 248 deal of flexibility in the analysis of particular examples.

This leaves many possible options for analysing alleged cases of faultless 250 disagreement. First, when A says 'vegemite is tasty' and B responds 'it is not', 251 A may be wrong in presupposing that her standard of state regarding vegemite 252 is shared by the community. B's dissenting voice suggests that the standard may 253 actually not be shared. If that is so, then A is at fault (and must retreat to the 254 subjective statement 'I find it tasty'). Second, A is free to maintain his statement 255 regardless of B's dissension, by suitably adjusting 'the community' and excluding 256 B from it. For example, A may judge that B departs, by his bad taste, from the 257 standards of the community. If this is true, then, from A's point of view, $B$ is at 258 fault. However we interpret the case, the disagreement is not faultless.

Kölbel points out an implication of my view: whenever A wrongly presupposes 260 that her standard of taste is shared by the community, she fails to express a complete 261 Austinian proposition, for the consensual standard of taste she invokes, and against 262 which she evaluates the lekton as true, does not actually exist. As he writes,

The context of utterance fails to determine a situation of evaluation. It's like uttering 'it is

\footnotetext{
${ }^{5}$ There are exceptions. In episodic uses referring to a particular experience ('it was tasty') the judge is the experiencer rather than any community.
} 
On that basis Kölbel raises the following objection:

According to Recanati's account, we cannot, when talking to one another, correctly assert that the picture is beautiful. For if we do so we commit a failure of presupposition similar to that of someone who asserts that it's raining intending to say something concerning Cockaigne. But no such failure seems to be involved. We take it to be quite normal to have diverging views on the beauty of pictures, but do not think that this prevents us from successfully asserting to one another that pictures are or are not beautiful. On Recanati's view, our assertions will lack a semantically complete content. So at the very least Recanati's account would have to allow that when we are talking about matters of taste, failing to assert something with a semantically complete content is not in any way a linguistic failing. For this type of situation seems to be absolutely standard. (Kölbel p. 20)

I find the objection interesting and worthy of a detailed response, based on a 278 distinction between three types of case.

As Kölbel must admit, there are cases for which the notion of failure straight- 280 forwardly applies. The speaker often retreats to a weaker position (the subjective 281 statement 'I find it tasty') when she discovers that the hearer dissents. That retreat 282 reveals that the speaker considers herself to have been at fault when she made the 283 stronger, objective claim.

On my account, however, presupposition failure (hence lack of determinate 285 content) is only one option, corresponding to the case where A is at fault. 'Adjusting' 286 the target community so as to make B's dissension irrelevant and rejecting his 287 standard of taste as faulty (i.e. contrary to the community's standard) is another 288 option, which need not involve any failure on the speaker's part. Of course, if the 289 speaker is right, it is the hearer who is now at fault.

I agree with Kölbel that there are also cases of a third type: cases of 'faultless 291 disagreement' such that no failure whatsoever is involved on the part of either 292 speaker or hearer. The protagonists may enter an episode of sustained disagreement 293 in which both parties (re)affirm diverging views without ever retreating to a weaker, 294 subjective statement of their taste.

Such cases raise a problem for my framework, Kölbel says. Each protagonist 296 vacuously refers to a communal standard that is being negociated and is not yet 297 established. It follows that no determinate Austinian proposition is expressed (this 298 is like referring to Cockaigne). For that reason, the utterance is, or should be, 299 neither true nor false. But this conclusion-that judgements of taste in situations of 300 sustained disagreement do not have a complete content and fail to determine a truth- 301 value-seems incompatible with the observation that such cases are 'absolutely 302 standard' and involve no linguistic failing.

But I don't think the conclusion and the observation are actually incompatible. 304 Following Kölbel's own suggestion, I want to 'allow that when we are talking 305 about matters of taste, failing to assert something with a semantically complete 306 content is not in any way a linguistic failing'. I agree that sustained disagreement 307 is faultless-it involves no failing of any sort. It is faultless because no standard of 308 taste is antecedently given as the standard of the local community formed by the 309 protagonists; it is up for grabs (up for negociation) what the communal standards 310 are. Each protagonist tries to impose his or her standards, to make them the standards 311 


\section{Author's Proof}

13 About the lekton: Response to Max Kölbel

of the local community. Each protagonist is entitled to do so, so there is no 'failure' 312 (no 'fault') when one does. Still, I suggest, the utterances of the protagonists lack 313 absolute truth-conditions.

I propose that, in sustained disagreement about matters of taste, the interlocu- 315 tors's moves and countermoves ('vegemite is tasty', 'no, it is disgusting') are (i) 316 neither true nor false, yet (ii) perfectly felicitous (involving no 'failure'). That 317 conjunctive property - truth-valueless yet felicitous-is not unheard of: imperative 318 utterances also have it. The lack of truth and falsity entails infelicity for assertions, 319 which aim at truth, but it does not entail infelicity for other speech acts. So it is 320 worth asking which speech act is performed by the utterances at stake. 321

In sustained disagreement the interlocutors negociate the standards for the local 322 community they form. I propose that their utterances (e.g. 'vegemite is tasty') are 323 not assertions but prescriptions, inviting the hearer to adopt standards with respect 324 to which the lekton is true. The speaker offers her own standards as the coordinative 325 standard for the community. A counter-proposal by the hearer is a fully legitimate 326 move: the hearer may resist the speaker's invitation and offer his own standard as 327 the one they should adopt. So the disagreement persists and it is faultless. ${ }^{6} \quad 328$

I conclude that 'vegemite is tasty' can be either an assertion (in which case 329 disagreement cannot be faultless) or a prescription (in which case it can be). If it 330 is an assertion, the context must determine a topic situation with respect to which 331 it can be evaluated. The typical lack of such a determinate situation in episodes of 332 disagreement about taste, where the communal standard is unsettled, is a problem if 333 the utterance is an assertion; but it raises no problem if the utterance is a prescription. 334 (We can also, and presumably should, accept that there are mixed cases, indeed a 335 whole continuum of cases with an assertive and an prescriptive component; but I 336 will ignore this complication here.)

When the utterance is a prescription the content of the speech act is a relativized 338 proposition (lekton): that vegemite is tasty. The speaker tries to get the hearer (and 339 the local community more generally) to adopt standards which make that lekton 340 true. The lekton has truth-at conditions (it is true at certain standards and false at 341 others) but it carries no absolute truth-conditions in these circumstances, for lack of 342 a communal standard accepted by all parties. The conversation aims at establishing 343 such a standard. Until it is settled, no determinate, stable situation of evaluation 344 is provided to turn the lekton into a full Austinian proposition. The speech act is 345 nondefective, however. It has a determinate force and a determinate content the 346 lekton) but, like orders, it does not allow for truth-evaluation. 347

I think this proposal, of the classical expressivist variety, fares better than 348 Kölbel's. Kölbel thinks cases of faultless disagreement are cases in which A and 349 B cannot accept the lekton endorsed by the other (from their own perspective) 350 without changing their mind. But that characterization fails to exclude cases 351 of misunderstanding like the example I gave earlier: I call you on the phone, 352

\footnotetext{
${ }^{6}$ This is similar to MacFarlane's suggestions regarding 'context coordination' (see Perspectival Thought, fn. 35 pp. 93-94).
} 


\section{Author's Proof}

and commenting upon my situation I say 'It is raining'; you respond 'No, it 353 isn't', meaning that there is no rain in your situation. In that example, there is 354 misunderstanding rather than genuine disagreement; but that is also a case in which 355 the interlocutors cannot accept the lekton endorsed by the other (from their own 356 perspective) without changing their mind. ${ }^{7}$

\section{References}

Cohen, J., \& Kehler, A. (forthcoming). Conversational eliciture.

Dummett, M. (1973). Frege: Philosophy of language. London: Duckworth.

Dummett, M. (1981). The interpretation of Frege's philosophy. London: Duckworth.
Dummett, M. (1993). The logical basis of metaphysics. London: Duckworth.

Evans, G. (1979). Reference and contingency. The Monist, 62, 161-189. 363

AQ3 Kölbel, M. (2016). About concerns. In I. Depraetere(Ed.), Semantics and pragmatics: Drawing a 364 line (pp. XX-XX). Cham: Springer.

Lewis, D. (1979). Attitudes De Dicto and De se. Philosophical Review, 88, 513-543. 366

Lewis, D. (1980). Index, context and content. In S. Kanger \& S. Ohman (Eds.), Philosophy and 367 grammar (pp. 79-100). Dordrecht: Reidel. 368

Ninan, D. (2008). Imagination, content, and the self. $\mathrm{PhD}$ dissertation, MIT. 369

Perry, J. (1986). Thought without representation. Proceedings of the Aristotelian Society, 60, 370 $137-151$.

Perry, J. (2014). The self as subject and object. The Romanell lecture, Central Division Meetings 372 of the APA.

Prior, A. (1977). with K. Fine, Worlds, times, and selves. London: Duckworth.

Recanati, F. (2004). Literal meaning. Cambridge: Cambridge University Press. 375

Recanati, F. (2007). Perspectival thought. Oxford: Oxford University Press. 376

Recanati, F. (2010). Truth-conditional pragmatics. Oxford: Clarendon. 377

Wittgenstein, L. (1958). The blue and brown books. Oxford: Blackwell. 378

\footnotetext{
${ }^{7}$ This paper benefitted from support from the French Agence Nationale de la Recherche under grant agreement $n^{\circ}$ ANR-10-LABX-0087 IEC and grant agreement $n^{\circ}$ ANR-10-IDEX-0001-02 PSL.
} 


\section{Author's Proof}

\section{AUTHOR QUERIES}

AQ1. Please provide section heading here and subsequence occurrences $P$ AQ2. Please update the reference Cohen and Kehl sforthcoming) if possible. $\Omega$ AQ3. Please update page range for Kölbel (2016). 